\title{
Outcomes of an Australian Nursing Student-led School Vision and Hearing Screening Program
}

\section{Introduction}

There is considerable debate about the effectiveness of screening in schools. There is evidence that children with severe hearing loss have significant behavioural problems (Theunissen et al., 2014) and that otitis media with effusion (OTE) or 'glue ear' may lead to problems with language development and behaviour (Simpson et al., 2007). Similarly, young children who fail a visual screening test may be more at risk of poor academic performance two years later (Marshall, Meetz, \& Harmon, 2010) and may experience poor quality of life as a result of conditions such as Amblyopia, or lazy eye, (Powell \& Hatt, 2009). Consequently, many health experts are strongly in favour of school screening as evidenced by the European Consensus Statement on hearing screening for pre-school and school-age children (Skarżyński \& Piotrowska, 2012).

However, there is little high quality evidence in favour of screening for hearing loss or visual impairment, given the difficulties of collecting such data (Mathers, Keyes, \& Wright, 2010; Murray, Low, Hollis, Cross, \& Davis, 2007; Powell \& Hatt, 2009; Powell, Wedner, \& Hatt, 2004; Simpson et al., 2007). Perhaps the lack of high quality evidence should not be taken as evidence that screening is not beneficial, given that the impact of screening will vary according to geographical and socio-economic factors (Powell \& Hatt, 2009; Powell et al., 2004). There will also be variability according to the prevalence of hearing problems or visual impairments in a given population, and issues such as poor school attendance will affect the data collected (Sharma, Congdon, Patel, \& Gilbert, 2012). 
In developing countries around the world, the level of OTE can be very high. For example, in Malaysia 13.8\% of children aged 5-6 were found to have OTE, and 15\% suffered from a mild hearing loss. There was also a correlation between mild hearing loss and academic performance based on their average mark (Daud, Noor, Rahman, Sidek, \& Mohamad, 2010). In Nigeria, 13.9\% of pre-school children aged 3-6 years old suffered with OTE (Adebola, Ayodele, Oyelakin, Babarinde, \& Adebola, 2013). In 1998, 774 children in 11 remote communities in the Northern Territory of Australia were screened and found to have very high levels of trachoma (26\%), nearly one-third failed a hearing test, and 3\% failed visual acuity. At this stage, it was recommended that a school-age child health surveillance program be instigated (Paterson, Ruben, \& Nossar, 1998).

Poor hearing and sight outcomes continue to be discovered among Aboriginal and Torres Strait Islander children in Australia. Mobile telehealth vans travelling to Aboriginal schools in Queensland have reported that $41 \%$ of children failed a hearing screening test and 15\% an eye test conducted by an Aboriginal Health Worker (Bensink et al., 2010). This method has been described as an effective method of routine screening for at risk children (Smith et al., 2012).

The Australian Federal Government introduced a 'Healthy Kids Check’ as part of their Enhanced Primary Care Program which covered growth, weight, obesity, vision, hearing, oral health, enuresis, encopresis, allergic disease, and food allergies, despite the dearth of evidence relevant to child health surveillance in primary health care (Alexander \& Mazza, 2010). However, there is no agreed vision or hearing screening 
protocol for Australian children, with States and Territories operating different school programs in an ad hoc manner (Alexander \& Mazza, 2010; Boptom, Sampson, Hendicott, \& Wood, 2013).

This study was designed to describe and evaluate the implementation difficulties related to a vision and hearing screening program initiated by student nurses in a student-led clinic in an underserved and disadvantaged community and conducted in local schools that have a high proportion of Indigenous students.

\section{Method}

\section{Program overview and setting}

Nursing students of a University student-led clinic (Stuhlmiller \& Tolchard, 2015) were invited by two local elementary school principals to develop an 'eye and ear' screening program for children. While the schools did not have the staff or resources to provide screening, they recognized its importance. The nursing students devised two different approaches to the testing initiative to suit the needs of each school. One school opted for an outdoor health jamboree held at the park next to the student-led clinic. The jamboree included eye and ear testing as well as other health promotion activities such as dental health, fitness, and dreamtime stories. Three hundred and fifty children were screened by the nursing students at this event. Three hundred and ninety-one children from the other school were screened in their school gymnasium over several different days. Consent was obtained through the University Human Research Ethics Committee in order to collect data from the screening and determine follow up outcomes. Parents answered a questionnaire concerning their child's vision 
and hearing and provided consent to have their child screened and participate in the study.

The nursing students were trained in the use of basic vision testing using a Snellen chart to test visual acuity. It was not possible to screen for actual hearing, so students used an otoscope to examine the ears for problems known to adversely affect hearing. The students conducted these initial screenings under the supervision of a nursing facilitator. Any testing that was unclear or suspicious was referred to a vision or hearing specialist onsite for further testing. A nurse practitioner was authorized to provide prescriptions and referrals.

\section{Participants and research approach}

A cross-sectional descriptive design was used to inform the research. Participants were school aged children from two elementary schools (School H and School W). Each child was offered screening of eyes, ears or both as determined by parental consent. Included with the consent form, parents had answered a questionnaire pertaining to their child's vision and hearing.

There were 11 items in the scale which were shown to be moderately reliable using the Kuder-Richardson 20 Test (KR-20) for reliability of dichotomous variables giving an alpha of .654. The items included in the questionnaire were: 1 . Do you have concerns about your child's eyes? 2. Is your child under the care of a specialist for any eye problems? 3. Does your child have problems learning at school or paying attention due to their eye problems? and 4. Is there a family history of eye problems? The same questions were repeated for hearing. In addition, parents were also asked: 1 . 
Does your child complain of headaches? 2. Does your child have a history of ear infections? and 3. Does your child complain of pain or have balance issues? Two further questions were included in the questionnaire but were not reliable and so were removed. They were: Does your child or anyone in the family have a history of diabetes? and 2. Are there any smokers in the family?

Using an Unweighted Least Squares, Varimax rotation with Kaiser Normalization exploratory factor analysis identified three factors which were consistent for eye problems (four items), ear problems (five items) and specialist care (two items). All items loaded above .500 with the exception of both eye and ear family history items which loaded between .339 (family history of eye problems) and .250 (family history of ear problems). However, these items maintained the integrity of the overall fit and so were retained. The Kaiser-Meyer-Olkin (KMO) test resulted in a value of .634 and Bartletts Test of sphericity yielded a $\mathrm{p}<.001$, indicating the factors to be reliable.

\section{Physical tests}

Eye screening was conducted using the Snellen chart with children at 6 meters' distance. For the very young and those unable to read letters, an animal chart was used. The teachers advised which chart to use for specific children. Visual acuity checked left eye and right eye and then both. If findings were outside normal range, they were further examined by an onsite specialist. A letter to parents explaining the findings along with a referral letter to an optometrist and prescriptions written by the nurse practitioner were given to the teacher to forward to the parent for follow up if deemed necessary. 
Basic otoscopy was used by students for ear screening. Where a child was found to have ear scaring, wax build up, or fluid visible behind the tympanic membrane, tympanometry was performed by a specialist for checking the condition of the middle ear. Tympanometry provides useful quantitative information about the presence of fluid in the middle ear, mobility of the middle ear system, and ear canal volume. Again, letters to parents, referrals to a specialist, and prescriptions were sent to parents via the teachers. In cases where a child experienced abnormal ear results follow-up was urged.

For children who required antibiotics for ear infections a prescription was sent home on the day of the screening event. Schools then follow up shortly afterwards to ensure that prescriptions had been collected by the parents and given to the children. For Aboriginal families with limited financial resources, Close the Gap forms were sent home so they could get the prescriptions filled for free. Close the Gap is an organisation that ensure all people from Aboriginal communities are able to access healthcare regardless of their ability to pay. Medicare Local—a public healthcare agency — assisted in chasing up families with children who required follow-up. For some children, follow-up was difficult or unable to be done due to families moving away or children living with relatives. On a number of the mass screening days’ free glasses were arranged with a local optometrist if the student required glasses. Where possible, the mass screening team returned to the same school to perform repeat eye and ear screening to see if issues were resolving.

\section{Data analysis}


The data analysis provides a descriptive overview of the overall presentation of children with vision and hearing problems and parental views of the impact of such problems on their child's school experience. All data was entered into a statistical analysis software program (SPSS V.24). A descriptive analysis was prepared for all data. Non-parametric analyses were conducted on group data.

\section{Findings}

\section{Screening results}

The findings for each child were documented. There were six screening events held over a two-month period. The first event identified $20 \%$ of children of nearly 350 needing additional testing and treatment. Subsequently five other events were conducted in the elementary schools providing data on over 391 additional children which yielded similar numbers requiring further testing (22\%). A small percentage (around 10\%) required specific treatment on the day of the screening.

\section{Demographics data}

Seven-hundred and forty-one children received screening for either eyes or nears or both. Table 1 presents demographic data for children across both schools (W \& H) included in the study. The only significant difference found was the proportion of children from Aboriginal \& Torres Strait Islander (ATSI) backgrounds between the two schools. No differences were observed in terms of gender composition and the proportion of school years represented.

Insert table 1 here 


\section{Eye and ear presentations}

As mass screening events were free, therefore it was unsurprising that the majority of participants had both eyes and ears tested (eyes \& ears, 95\%; ears only, 5\%; eyes only, $0 \%$ ). The children who did not have their eyes tested was due to the child refusing the test. In these cases, parents were given advice on the benefits of the child having this test in the near future.

The data shows $14.4 \%$ of children failed the visual acuity test, which matched parental concerns over their child's eyesight (13.3\%). Parents reported high levels of eye problems in members of the child's immediate family at $61.2 \%$. Parents also reported $21.9 \%$ of their children had problems at school due to their eyesight. Where a child had problems with their eyesight, on most occasions this was believed by their parents to have affected their ability to concentrate at school due to headaches (25.0\%) or to see the board properly (56.3\%).

Overall, $18.8 \%$ of children were experiencing some kind abnormal ear problem with 13.0\% of parents being concerned about their child's hearing (typical problems included abnormal ear tympanometry and glue ear). Of this group, 64.7\% of parents were concerned that their child had undiagnosed hearing problems. This included not hearing properly, speaking loudly, and having to turn the television and music up louder than expected. This was considered by parents to be affecting their child's ability to concentrate at school $\left(\chi^{2}(1,400)=31.12, p<.001\right)$. Parents were also concerned regarding their child's hearing which translated into them considering the child to be experiencing problems learning at school $\left(\chi^{2}(1,400)=8.23, p<.05\right)$. This was more evident in school $\mathrm{W}\left(\chi^{2}(1,400)=7.87, \mathrm{p}<.05\right)$. 
While there was some variation between schools, these were not significant across the whole population of participants. On the other hand, children from Aboriginal and Torres Strait Islander backgrounds were significantly more likely to experience abnormal ear problems $\left(\chi^{2}(1,598)=9.17, p<.05\right)$ but not eye problems $\left(\chi^{2}(1,598)=\right.$ 1.54, $p>$.05). Overall, 21.0\% of Aboriginal and Torres Strait Islander children experienced ear problems compared to $12.6 \%$ of Caucasian children. This difference was most pronounced in male Aboriginal and Torres Strait Islander children $\left(\chi^{2}(1\right.$, $598)=7.00, p<.05)$ across both schools.

While the proportion of Aboriginal and Torres Strait Islander children was higher in School $\mathrm{H}$, the greatest differences for those whom identified as ATSI were found in School W, where $24.3 \%$ experienced abnormal ear results $\left(\chi^{2}(1,598)=9.88, p<.05\right)$. The female Aboriginal and Torres Strait Islander children in School W were significantly more likely to experience ear problems $\left(\chi^{2}(1,598)=5.59, \mathrm{p}<.05\right)$. Differences were not associated with age, learning problems at school, or family history of ear problems.

\section{Follow up results}

An attempt was made to follow-up all children where abnormal eye or ear results had been found and follow-up appointments given to see if their problems were persisting. A small percentage required specific treatment on the day of the screening ( $\sim 10 \%)$. Follow-up most commonly included referral to an optometrist, assessment of antibiotic effectiveness, and general practitioner re-examining wax drop applications. 
It was not possible to determine how many children attended these follow-up sessions.

\section{Difficulties with follow up}

Challenges to follow up of the children included the lack of school nurses and resources. This meant that consistent follow-up could only happen with the will of the principal teacher and their staff. In the case of both schools in this study, despite overwhelming support of the project, poor resourcing of non-educational activities such as health initiatives, led to gaps in reporting. As a nursing student-led initiative, we had hoped that more of their clinical time could have been devoted to assisting with follow-up, data entry, and finding missing data. Some nursing students did dedicate additional hours to the project despite competing demands but, in the main, they were required to focus on clinic skills over research concerns.

When the initiative was planned, the lead school principal suggested that student performance measures could be easily accessed from school records and examined for changes resulting from improved hearing and vision. This was not the case. Summary performance scores were not kept on a regular basis nor could the impact of improvements be teased out or specifically correlated to treatment interventions. Confounding variables such as extra tutoring or enrolment into a special education programs could also account for changes.

\section{Discussion}

This study confirmed that eye and ear mass screening successfully identified a number of children with varying levels of problems that had not been previously 
detected. In this population, few attend their GPs or even have a GP and so only seek help when a crisis is reached by attending emergency departments. Therefore, a large number of children have ear or eye health concerns may go undetected for considerable periods of time, resulting in potential long-term damage physically, educationally, and relationally. It was also clear that parents were aware of the potential of the impact such problems were having on their children, especially with hearing and less so with vision problems. The benefits of early detection and treatment on a child's quality of life related to their ear problems has been shown (Williamson et al., 2015).

Aboriginal and Torres Strait Islander children were over represented in both schools compared with the Australian regional average of 21.8\% (Australian Bureau of Statsitics, 2013), but not so when considering the population from which they came (Profile.id, 2011). Even taking this into account, Aboriginal and Torres Strait Islander children experienced more eye and ear problems than Caucasian children. This was more pronounced in the school with a lower Indigenous population. In this group of children, cultural background may not have been the specific factor relating to their eye and ear problems, rather living in an underserved community with high rates of unemployment and poverty may be more indicative. This is a community with no amenities at all, such as a shop or bank, and with limited telecommunications access. This highlights the need for health and education to work collaboratively with the children and their parents to ensure that health issues are seen as a required arm to education practices. An example of this is found in the Coordinated School Health model in the United States of America (Lewallen, Hunt, Potts-Datema, Zaza, \& Giles, 
2015). Such a model would provide the framework to ensure that regular follow-up happens after events such as the eye and ear mass screenings.

However, case by case analysis did provide some anecdotal and speculative insights attributed to improved sight and hearing including resolved ear infections, suitable spectacles, and reduction of wax and fluid in the ears. This was confirmed by teachers who reported attention and learning benefits following screening and treatment.

Nursing students proved to be capable of setting up and delivering a successful screening program to meet the needs of each school. They not only gained new leadership skills in community collaboration and planning and clinical competence in problem detection, their ability to work with children and explain examinations in an age appropriate manner was remarkable. For example, a computer screen enabled ear images to be viewed on the spot by the children and explained by the student, thus making it a fun and meaningful shared activity. Nursing students also received widespread recognition in newsletters, reports, and word of mouth for the important service they provided. The shortage of clinical learning opportunities for nursing students coupled with the school resource deficits and lack of school nurses, created a valuable health and learning outcome.

\section{Conclusions}

It is known that early detection and treatment of health problems can improve function, performance, and well-being and can reduce the development of more serious health problems. This is particularly true for Aboriginal and Torres Strait 
Islander children who are five times more prone to hearing problems particularly otitis media than non-Aboriginal children (Gunasekera et al., 2007). Understanding more about the impact of mass screenings in an area with a high Aboriginal and Torres Strait Islander populations can help inform approaches that help to 'close the gap’ between Indigenous and non-Indigenous health outcomes (Burns \& Thomson, 2013). This study found that student nurses are a valuable workforce resource to be considered in filling the gaps and extending the role of school nurses in underserved, asset poor communities.

\section{Limitations and recommendations for future research}

The challenges to screening follow-up were identified. These shortcomings undermined the ability to specifically link and give power to the hypothesis that improved vision and hearing leads to improved school performance. The shortcomings of this study beg for better collaboration and understanding about the importance of school performance data availability prior to commencing any further data collection. Attempts to find missing data and to provide more complete data entry was also needed to increase the veracity of future study. The student, faculty, and stakeholders screening program committee has met and agreed to commit human resources for follow up and determine a means for measuring school performance changes in future.

\section{References}

Adebola, S. O., Ayodele, S. O., Oyelakin, O. A., Babarinde, J. A., \& Adebola, O. E. (2013). Pre-school hearing screning: Profile of children from Ogbomoso, Nigeria. International Journal of Pediatric Otorhinolaryngology, 77(12), 1987-1991.

Alexander, K. E., \& Mazza, D. (2010). The healthy kids check-is it evidence-based. Medical Journal of Australia, 192(4), 207-210. 
Australian Bureau of Statsitics. (2013). Census of Population and Housing: Understanding the Increase in Aboriginal and Torres Strait Islander Counts, 2006-2011. from ABS

Bensink, M. E., Brown, C., Elliott, G., Perry, C., Scuffham, P., \& Smith, A. C. (2010). The feasibility of a community-based mobile telehealth screening service for Aboriginal and Torres Strait Islander children in Australia. Telemedicine and e-Health, 16(9), 950-956.

Boptom, S. H., Sampson, G. P., Hendicott, P., \& Wood, J. M. (2013). Review of guidelines for children's vision screenings. Clinical and Experimental Optometry, 96(5), 443-449. doi: 10.1111/cxo.12029

Burns, J. F., \& Thomson, N. J. (2013). Review of ear health and hearing among Indigenous Australians Australian Indigenous HealthInfoNet.

Daud, M. K. M., Noor, R. M., Rahman, N. A., Sidek, D. S., \& Mohamad, A. (2010). The effect of mild hearing loss on academic performance in primary school children. International Journal of Pediatric Otorhinolaryngology, 74, 67-70. doi: 10.1016/j.ijporl.2009.10.013

Gunasekera, H., Knox, S., Morris, P., Britt, H., McIntyre, P., \& Craig, J. C. (2007). The spectrum and management of otitis media in Australian indigenous and nonindigenous children: a national study. The Pediatric infectious disease journal, 26(8), 689-692.

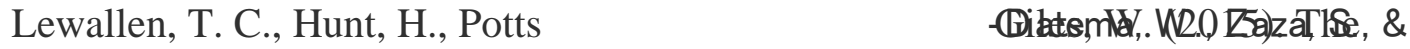
Whole School, Whole Community, Whole Child model: a new approach for improving educational attainment and healthy development for students. Journal of School Health, 85(11), 729-739.

Marshall, E. C., Meetz, R. E., \& Harmon, L. L. (2010). Through our children's eyes The public health impact of the vision screening requirements for Indiana school children. Optometry, 81(2), 71-82. doi: 10.1016/j.optm.2009.04.099

Mathers, M., Keyes, M., \& Wright, M. (2010). A review of the evidence on the effectiveness of children's vision screening. Child: Care, Health and Development, 36(6), 756-780. doi: 10.1111/j.1365-2214.2010.01109.x

Murray, N. G., Low, B. J., Hollis, C., Cross, A. W., \& Davis, S. M. (2007). Coordinated school health programs and academic achievement: A systematic review of the literature. Journal of School Health, 77(9), 589-600.

Paterson, B., Ruben, A., \& Nossar, A. (1998). School screening in remote Aboriginal communities. ANZJPH, 22(6), 685-689. doi: 10.1111/j.1467842X.1998.tb01470.x

Powell, C., \& Hatt, S. R. (2009). Vision screening for amblyopia in childhood. Cochrane database of systematic reviews(3), Art No. CD005020. doi: 10.1002/14651858.CD005020.pub3

Powell, C., Wedner, S., \& Hatt, S. R. (2004). Vision screening for correctable visual acuity deficits in school-age children and adolescents. Cochrane database of systematic reviews(4), Art No. CD005023. doi: 10.1002/14651858.CD005023.pub2

Profile.id. (2011). West Tamworth (Coledale): Population, dwellings and ethnicity. Sydney, Australia.

Sharma, A., Congdon, N., Patel, M., \& Gilbert, C. (2012). School-based approaches to the correction of refractive error in children. Survey of Opthalmology, 57(3), 272-282. doi: 10.1016/j.survophthal.2011.11.002

Simpson, S. A., Thomas, C. L., van der Linden, M., macMillan, H., van der Wouden, J., \& Butler, C. C. (2007). Identification of children in the first four years of 
life for early treatment of otitis media with effusion. Cochrane database of systematic reviews(1), Art No. CD004163. doi:

10.1002/14651858.CD004163.pub2

Skarżyński, H., \& Piotrowska, A. (2012). Screening for pre-school and school-age hearing problems: European Consensus. International Journal of Pediatric Otorhinolaryngology, 76(1), 120-121.

Smith, A. C., Armfield, N. R., Wu, W.-I., Brown, C., \& Perry, C. (2012). A mobile telemedicine-enabled ear screening service for Indigenous children in Queensland: Activity and outcomes in the first three years. Journal of Telemedicine and Telecare, 18(8), 485-489. doi: 10.1258/jtt.2012.GTH114

Stuhlmiller, C., \& Tolchard, B. (2015). Developing a student-led health and wellbeing clinic in an underserved community: collaborative learning, health outcomes and cost savings. BMC Nursing, 14(1), 32.

Theunissen, C. P. M., Rieffe, C., Kouwenberg, M., De Raeve, L. J. I., Soede, W., Briaire, J. J., \& Frijns, J. H. M. (2014). Behavioural problems in school-aged hearing-impaired children: The influence of sociodemographic, linguistic, and medical factors. European Child \& Adolescent Psychiatry, 23, 187-196. doi: 10.1007/s00787-013-0444-4

Williamson, I., Vennik, J., Harnden, A., Voysey, M., Perera, R., Breen, M., . . . Raftery, J. (2015). An open randomised study of autoinflation in 4-to 11-yearold school children with otitis media with effusion in primary care. 